\section{ON THE PROGNOSTIC VALUE OF HÆMOPTYSIS.*}

BY J. B. BRADBURY, M.D., M.R.C.P.,

Physician to Addenbrooke's Hospital. Cambridge ; Medical Lecturer in Downing College ; etc.

H AmOPTYSIS is usually regarded by nedical men as a symptom of such grave import, that when a patient informs us he has been spitting blood we regard it as tantamount to telling us that he is suffering from organic disease either of the lungs or heart.

The chief object which $I$ have in view in this paper is to endeavour to show that pulmonary hæmorrhage is not a symptom of such unfavourable augury as we are apt to consider it, but that it not unfrequently occurs in persons in whom neither phthisis nor serious cardiac disease can be detected.

It will be well at the outset to enumerate the chief conditions under which hæmoptysis usually takes place, and then to consider the value to be attached to its occurrence in the several diseases of which it is but one form of expression. Expectoration of blood (exclusive of those cases in which it arises from a blow on the thorax, or from the mouth and fauces, or from ulceration of the larynx and trachea) may occur as follows : In vicarious menstruation; in hysterical women, though the catamenia are regular; in pregnant and suckling women; in the hæmorrhagic diathesis, purpura, scurvy, etc.; in bronchitis ; in emphysema and asthma; in pneumonia ; in pulmonary consumption ; in pulmonary apoplexy; in disease of the heart and great vessels; etc.

The hæmoptysis which is vicarious of menstruation is probably the most favourable form of blood-spitting. A short time ago a young woman came to me stating that she was spitting blood. Upon inquiry, I found that she had no symptoms indicative of pulmonary disease beyond the raising of blood and a slight cough; she had not, however, menstruated per vaginam for a considerable time. Physical examination of her chest revealed nothing abnormal. I ascertained that the hæmoptysis occurred periodically about once a month. I accordingly concluded that the case was one of menstruation by the lungs; and the result of the treatment adopted served to confirm this view of the nature of the case.

I am aware that it has been stated, on very high authority, that these cases ultimately turn out to be phthisical, and I do not wish it to be understood that I am of opinion that all such cases terminate so favourably as the one I have just recorded ; indeed, I have at present an outpatient at the hospital who every month suffers from epistaxis and hæmoptysis-in all probability vicarious of the menstrual dischargeand in whose lungs there are unmistakable signs of pulmonary mischief; still this is probably a mere coincidence, and is not necessarily connected with the diverted course of the catamenia. Dr. Pollock of the Brompton Hospital, in his work on the Elements of Prognosis in Consumption, writes as follows: "When menstruation is suddenly checked, a hæmoptysis is a frequent event, and may be regarded as vicarious, and with less import of pulmonary mischief than under other circumstances" (pp. 297-298).

Hæmoptysis also occurs in nervous and hysterical women, without there being any irregularity of the catamenia or any pulmonary or cardiac disease. This form usually ceases when the climacteric period is passed, and never returns.

The hæmoptysis which sometimes occurs in pregnant and suckling women is a form which is not sufficiently recognised by medical men in this country-little, if any, rotice being taken of it in the English textbooks on medicine. Trousseau thus speaks of it: "There are some women who, during pregnancy, and others who, during the whole time they are nursing, spit blood; the hæmorrhage ceases spontaneously after delivery, or at the end of lactation, as the case may be, and is not symptomatic of pulmonary tubercle nor of cardiac disease." (Clinical Medicine, vol. iii, p. I 40 ; New Syd. Soc.)

It is not my business to explain the cause of the hæmorrhage in the above cases, as I am only concerned with the prognosis, which, from what I have said, you will have concluded to be favourable.

Persons who suffer from what, for want of a better term, is called the hæmorrhagic diathesis, are liable to attacks of profuse hæmoptysis. A case of this kind is recorded by Dr. George Johnson, in the BRITISH MEDICAL Journal for Feb. I2th, I870. Dr. Johnson's patient was a blacksmith, who had frequent attacks of pulmonary hæmorrhage extending over a period of twelve years, and who, at the time of Dr. Johnson's writing, pretty certainly had no organic disease of the lung either as a cause or a consequence.

Closely allied to these cases of hæmoptysis, are those occurring in habitual drunkards, and in scurvy, purpura, and the hæmorrhagic ex-

\footnotetext{
* Read before the Cambridge and Huntingdon Branch.
}

anthemata, e.g., typhus, small-pox, etc. In all these instances we probably have a morbid tenderness of the walls of the blood-vessels, occurring without any assignable cause in the hæmorrhagic diathesis; but in chronic alcoholism, purpura, scurvy, etc., it is probably owing to a deterioration of the blood "so modifying the nutritive state of the walls of the blood-vessels as to impair their resisting power"-(Niemeyer).

If the habitual toper can be induced to indulge less in his favourite drink, the prognosis is not unfavourable. I have in my recollection the case of a young man whom I occasionally saw when I was a pupil some thirteen or fourteen years ago, who suffered from repeated attacks of this form of hæmorrhage, and who seemed completely to recover from several of them. He could not, however, be induced to forego the pleasures of the bottle, and he ultimately fell a victim to pulmonary consumption, probably induced by one of these attacks of hæmoptysis in a way which I shall presently explain. I have also a case of this kind under my care at the present time, which I am watching with considerable interest. The patient has had three severe attacks of hæmoptysis since last August, and is at the present time progressing rapidly towards convalescence from the last attack; the lung-mischief not having as yet, however, entirely disappeared.

There is one form of bronchitis with which spitting of blood is generally associated-I allude to the plastic form. In some of these cases the bronchorrhagia is the first symptom. The hæmoptysis may recur at intervals until the fibrinous casts of the bronchial tubes are expelled. Of thirty-four cases of this disease recorded by Dr. Peacock in the fifth volume of the Pathological Transactions, there was entire recovery in twenty cases, four became chronic, and ten died, so that nearly sixty per cent. recovered.

Ordinary acute bronchitis is also sometimes attended with the expectoration of bloody sputa, and even with copious hæmoptysis ; and these are the cases in which the prognostic powers of the physician become sorely taxed. For instance, a patient has an attack of bronchitis supervening upon a severe catarrh, and during the attack the expectoration is streaked with blood. There may be no evidence of pulmonary mischief beyond the bronchitis; i.e., no diminished respiratory murmur nor prolonged expiration, nor dulness on percussion under either clavicle, nor any bronchial breathing, nor, in a word, any physical signs indicative of consolidation of the lung. Now, what is our prognosis in such a case as this? If there be no strong hereditary tendency to phthisis in the family, and if the bronchial mischief disappear under the administration of appropriate remedies, we may augur favourably of the case ; if, on the other hand, the predisposition to phthisis be great, and the catarrhal symptoms in either apex be persistent, the prognosis is grave. I have at present under my care a young man of the age of 18 , whose case is of the latter type, and I confess I am afraid he will become consumptive. In these cases especially, however, our prognosis must be rather a balance of probabilities than one of absulute certainty,

Blood-spitting is a more frequent symptom of pulmonary emphysema than is generally supposed. Dr. Walshe says : "Emphysema of the lung, as its anatomy would prepare us to expect, antagonises pulmonary hæmorrhage of all kinds" (Diseases of the Lungs, 3 rd ed., p. 416.) This is a statement which I cannot endorse, for I had lately under my care two patients suffering from emphysema, accompanied with hæmoptysis, in whom the most careful physical examination failed to detect any evidence of phthisis, or of considerable hypertrophy of the right side of the heart. Cases of the same kind have been observed by other physicians, amongst whom I may mention Dr. George Johnson, who writes as follows : "In several cases of hæmoptysis that have come under my observation, emphysema of the lung has been the only structural change that I could discover." (BRIT. MED. Jour., Feb. I2th, I87o.)

Persons with emphysema of the lung frequently live to a great age ; hence in these cases a favourable prognosis may generally be given. Hæmoptysis occasionally occurs in cases of severe asthma, and sometimes continues for so long a period as one month. The quantity of blood expectorated varies from a few streaks to as much as a pint. Dr. Hyde Salter says, "where it has once occurred it is very apt to occur again. . . . In one case that came under my observation, this hæmorrhage occurred for years at almost every attack. It evidently depended here on an unusual completeness of apnœa and its resulting bloodstasis; and yet no permanent injury was sustained by the lungs, and the ultimate recovery of the patient was complete". (On Asthma, and edition, pp. 88-89.)

Acute inflammation of the lungs is occasionally attended with copious hæmoptysis, in addition to the sputa being tinged with blood. I have not met with an instance of this kind, and writers seemed divided in opinion as to what the prognosis should be--one (Johnson) regarding the hæmorrhage as unconnected with tubercle, another (Walshe) stating that such cases are "almost positively connected with tubercular disease" (Diseases of the Lung, 3 rd edition, p. 42I). 
All who have carefully watched the revolution which medical opinions occasionally undergo must have been struck with the recent change in our ideas as to the nature and causes of pulmonary consumption. Since the time of Laennec, phthisis has been regarded by most physicians as due to tubercular deposit in the lungs, the result of a constitutional vice, which we call the tubercular diathesis. Recently, however, the views of Dr. Addison, which had not met with the attention they deserved in our own country, and which seem to have been altogether unknown on the continent, have been revived by Niemeyer and others, who regard pulmonary consumption as by no means always the result of tubercular deposit in the lung, but as being frequently the result of pneumonia, without any deposition of tubercle, although this new formation may in some cases co-exist with the products of inflammation of the lung; but the tubercles have in the majority of those cases only developed themselves at a later stage of the disease-their development only in very few cases preceding the pneumonic processes.

The products of any of the three forms of pneumonia-viz., common acute pneumonia, acute catarrhal pneumonia, and chronic catarrhal pneumonia, may undergo cheesy metamorphosis ; but the products of the latter form most frequently undergo this change, and lead to the formation of cavities in the lungs.

We may, then, have three forms of phthisis-viz., the pneumonic, the tuberculo-pneumonic, and the tubercular. The first two of these forms chiefly concern us as being connected with hæmoptysis, spitting of blood being a rare symptom in acute tuberculosis.

Phthisis caused by chronic pneumonia was not considered by Niemeyer to be a particularly dangerous disease. He says : "I do not hesitate to assert that the chronic inflammatory processes which lead to consolidation of the lung and to the formation of cavities, usually show a decided tendency to heal ; and that, under appropriate treatment, persons with extensive consolidation and great cavities may ofter for a long time be kept in a tolerable state-nay, comparatively even in a state of good health. The greatest danger to most phthisical patients is the development of tubercles" (Lectures on Phthisis, p. II.)

Niemeyer had also arrived at the conclusion, and rightly so, I think, that pulmonary hæmorrhage is sometimes a cause of consumptiona view which was entertained by Hippocrates, Cullen, and other old writers, who mention a "phthisis ab hæmoptöe". Cases have been recorded by Drs. Baümler, Weber, and George Johnson, which tend to confirm Professor Niemeyer's view; and there can now be little doubt of the fact that an attack of hæmoptysis may cause blood to be aspired into the smaller bronchi and air-cells of the lungs, where it may act as an irritant and set up inflammatory changes, the products of which may either undergo complete resolution or lead to the formation of cheesy products, which may ultimately soften and thereby shorten life. Such an accident may also happen during the progress of phthisis, but I am of opinion that it is not so common as Niemeyer would have us suppose ; and my experience certainly coincides with that of Walshe and others, who do not regard attacks of hæmoptysis, unless the hæmorrhage be very profuse, as materially accelerating the fatal issue.

It occasionally happens that hæmoptysis is the immediate cause of death in phthisis; and in these cases a rupture of a branch of the pulmonary artery in a vomica has preceded the fatal termination. Such cases are, however, not of frequent occurrence.

Unless, therefore, the hæmoptysis of phthisis be followed by an in. creased temperature, and by a persistent frequency and irritability of the pulse, our prognosis, quoad the hæmorrhage affecting the prolongation of life, need not in the majority of cases be unfavourable.

Pulmonary apoplexy, when attended with hæmoptysis, so frequently depends upon disease of the left side of the heart, especially of the mitral valve, that the prognosis in pulmonary infarction must necessarily be the same as that of the cardiac disease, of which it is a consequence, and which will presently come under our consideration. Before leaving the subject of pulmonary apoplexy I wish, however, to mention that it occasionally-very rarely, I acknowledge-proves rapidly fatal, owing to the copious hremoptysis which attends it. I have recorded in the BRITISH MEDICAL JOURNAL for Jan. $1_{4}$ th, 1871 , such a case in which the patient died within twenty minutes from the time of the supervention of the hæmorrhage, and in whose heart and lungs no organic mischief could be detected either before or after death, with the exception of a large patch of uncircumscribed pulmonary apoplexy at the base of the left lung, which was found only on post mortem examination.

In disease of the heart and great vessels, I must acknowledge that spitting of blood is a grave symptom, and that it by no means unfrequently warns us that the time has come when the physician, and the patient, too, alas! must capitulate to the disease against which the batteries of steel, digitalis, iodide of potassium, etc., can no longer hold out.

I have already trespassed too long on your patience, and will, in con- clusion, only remark that one of the objects which I have had in view in reading this paper has been to elicit discussion on this important subject, and to ascertain from those of greater experience than myself whether their opinions are in harmony or in discord with my own.

NOTES OF A VISIT TO THE MILITARY HOSPITALS AT BONN, WITH REMARKS UPON THE PHYSIQUE OF THE TROOPS RECENTLY RETURNED FROM FRANCE.

\section{By DYCE DUCKWORTH, M.D.,}

Assistant-Physician to St. Bartholomew's Hospital.

In the course of a holiday tour, and while at Bonn, I paid a visit to the military hospitals to see the last of the wounded in the recent war, and was very kindly conducted over them by Dr. Kalt, who, although a civil practitioner, had charge for some months of a number of the cases. There are now from two to three hundred wounded men in Bonn, and they lie in huts which were hurriedly built at the beginning of the war for the reception of French prisoners. As none of the latter were sent to Bonn, many of the huts were pulled down, and the remainder converted into small hospitals. They are built of wooden framework, into which concrete has been introduced, and are placed in rows upon the Exercier Platz. A large and airy hospital has also been made in the military riding school.

The former buildings very much resemble the Camp at Aldershot in their general aspect.

I learned that the wounded came from before Metz and Paris, a few from the engagements at Worth and Gravelotte, and many had confronted the army of General Faidherbe about Amiens and in the north of France. Only one Frenchman lay amongst them, the last of a considerable number. The cases were mostly the result of Chassepôt-bullet wounds, and some were from shells. There were many injuries to knee and wrist joints, and in not a few instances the balls were both known, and also believed to be, in the limbs. I saw no examples of conservative surgery.

On the whole, the hospitals proved very healthy, and the deaths reached a small percentage. An outbreak of hospital gangrene occurred early this year which threatened to prove formidable. Dr. Kalt employed, with the best results, the following treatment-actual cautery freely to the wounds, or pure carbolic acid in less severe cases, also wine and quinine plentifully. Every comfort appeared to be supplied to the men, and the air of the huts was quite satisfactory.

Many of the cases were quite convalescent, and while some were learning to use their crutches others were trying on wooden arms and legs. Dr. Kalt informed me that much venereal disease had befallen their troops while in France, and some severe cases of sloughing bubo, which had threatened to cause grievous loss of integument, were lying in one of the huts. Owing to great care, the ulcerations had been limited considerably. It is feared that syphilis may be found to spread in Germany, and to be introduced amongst the peasantry when the troops return to their homes, and this Dr. Kalt naturally regarded as a sad trophy of the war. He also believed the invasion of France would have a disastrous effect upon the morals of their younger soldiers, which was much to be deprecated.

Bonn seems likely to become a more important university than it has hitherto been, not but that it has always been one of the leading schools in Germany. In a few years the professors will possess almost unrivalled means of teaching technology and other applied sciences, and Bonn will only be second to the largest schools for clinical purposes by reason of the smallness of the town. At Poppelsdorf, one of the suburbs, large anatomical laboratories are being built, in addition to the splendid chemical and agricultural institutions already existing in that place, and there is at present a new obstetrical clinique being erected, with a river frontage, at the northern extremity of the town. Both medical and surgical cliniques are to be built adjoining the obstetrical one, so that remarkable changes in the appliances of the medical faculty are approaching. Bonn, like most other German medical schools, was bereft of her students last winter, as they volunteered for service in France as dressers.

While I was in Bonn the 8th regiment of the King's (Rhenish) Hussars made a triumphal entry into the town, and were received with intense enthusiasm and rejoicings. The men were in the finest possible condition, and no more active ur worklike troops could possibly be seen. They were bronzed and travel-stained, and gave infinitely more 